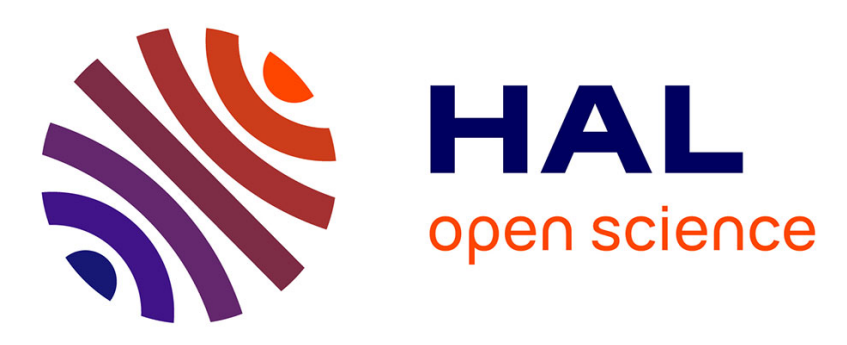

\title{
Cryogenic plasma-processed silicon microspikes as a high-performance anode material for lithium ion-batteries
}

Joe Sakai, Erwann Luais, Jérôme Wolfman, Thomas Tillocher, Remi Dussart, Francois Tran-Van, Fouad Ghamouss

\section{To cite this version:}

Joe Sakai, Erwann Luais, Jérôme Wolfman, Thomas Tillocher, Remi Dussart, et al.. Cryogenic plasma-processed silicon microspikes as a high-performance anode material for lithium ion-batteries. Journal of Applied Physics, 2017, 122 (15), pp.155103. 10.1063/1.4997713 . hal-01686032

\section{HAL Id: hal-01686032 https://hal.science/hal-01686032}

Submitted on 11 Feb 2022

HAL is a multi-disciplinary open access archive for the deposit and dissemination of scientific research documents, whether they are published or not. The documents may come from teaching and research institutions in France or abroad, or from public or private research centers.
L'archive ouverte pluridisciplinaire HAL, est destinée au dépôt et à la diffusion de documents scientifiques de niveau recherche, publiés ou non, émanant des établissements d'enseignement et de recherche français ou étrangers, des laboratoires publics ou privés. 


\section{Cryogenic plasma-processed silicon microspikes as a high-performance anode material for lithium ion-batteries}

Joe Sakai, Erwann Luais, Jérôme Wolfman, Thomas Tillocher, Rémi Dussart, Francois Tran-Van, and Fouad Ghamouss

Citation: Journal of Applied Physics 122, 155103 (2017);

View online: https://doi.org/10.1063/1.4997713

View Table of Contents: http://aip.scitation.org/toc/jap/122/15

Published by the American Institute of Physics

\section{Articles you may be interested in}

Reconfigurable origami sonic barriers with tunable bandgaps for traffic noise mitigation

Journal of Applied Physics 122, 154901 (2017); 10.1063/1.4991026

Low surface damage dry etched black silicon

Journal of Applied Physics 122, 143101 (2017); 10.1063/1.4993425

Influence of metal electrode on the performance of $\mathrm{ZnO}$ based resistance switching memories

Journal of Applied Physics 122, 154301 (2017); 10.1063/1.4996975

Temperature induced phase transformations and negative electrocaloric effect in ( $\mathrm{Pb}, \mathrm{La})(\mathrm{Zr}, \mathrm{Sn}, \mathrm{Ti}) \mathrm{O}_{3}$ antiferroelectric single crystal

Journal of Applied Physics 122, 154101 (2017); 10.1063/1.4986849

Internal stress and opto-electronic properties of $\mathrm{ZnO}$ thin films deposited by reactive sputtering in various oxygen partial pressures

Journal of Applied Physics 122, 155306 (2017); 10.1063/1.4996453

Influence of tetragonality (c/a) on dielectric nonlinearity and direct current (dc) bias characteristics of (1x) $\mathrm{BaTiO}_{3}-\mathrm{BBi}_{0.5} \mathrm{Na}_{0.5} \mathrm{TiO}_{3}$ ceramics

Journal of Applied Physics 122, 154103 (2017); 10.1063/1.5000019

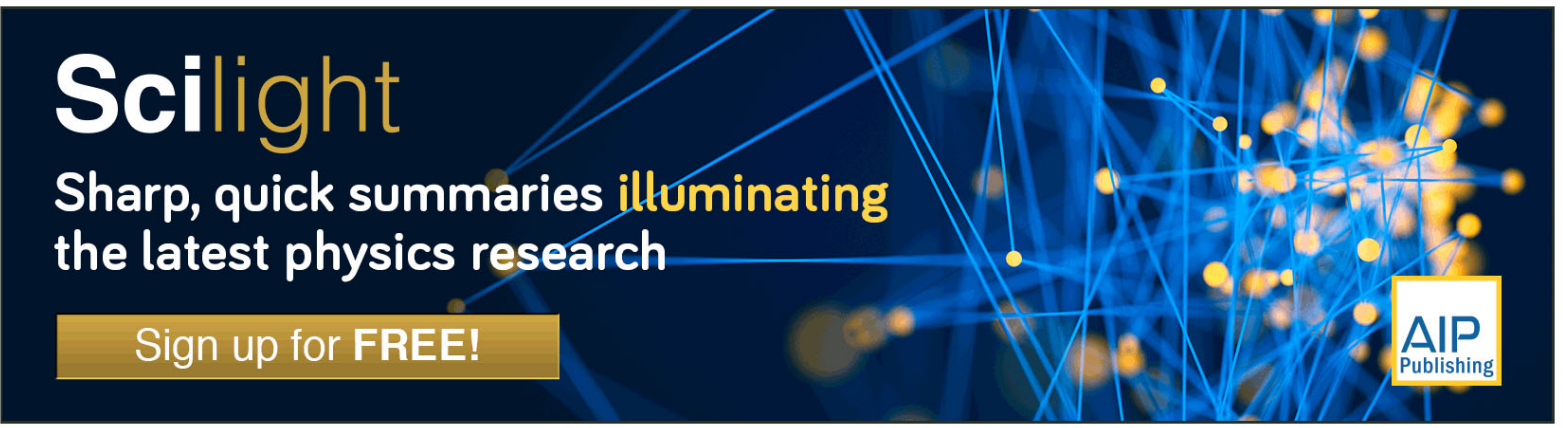




\title{
Cryogenic plasma-processed silicon microspikes as a high-performance anode material for lithium ion-batteries
}

\author{
Joe Sakai, ${ }^{1, a)}$ Erwann Luais, ${ }^{1,2}$ Jérôme Wolfman, ${ }^{1}$ Thomas Tillocher, ${ }^{3}$ Rémi Dussart, ${ }^{3}$ \\ Francois Tran-Van, ${ }^{2}$ and Fouad Ghamouss ${ }^{2}$ \\ ${ }^{1}$ GREMAN, UMR 7347 CNRS/Université François Rabelais de Tours, Parc de Grandmont, 37200 Tours, \\ France \\ ${ }^{2}$ PCM2E, EA 6299 Université François Rabelais de Tours, Parc de Grandmont, 37200 Tours, France \\ ${ }^{3}$ GREMI, UMR 7344 CNRS/Université d'Orléans, 14 rue d'Issoudun, B.P. 6744, 45067 Orléans, France
}

(Received 26 July 2017; accepted 3 October 2017; published online 19 October 2017)

\begin{abstract}
Micro- or nano-structuring is essential in order to use $\mathrm{Si}$ as an anode material for lithium ion batteries. In the present study, we attempted to use Si wafers with a spiky microstructure (SMS), the socalled black-Si, prepared by a cryogenic reactive ion etching process with an $\mathrm{SF}_{6} / \mathrm{O}_{2}$ gas mixture, for Li half-cells. The SMS with various sizes of spikes from $2.0 \mu \mathrm{m}$ (height) $\times 0.2 \mu \mathrm{m}$ (width) to $21 \mu \mathrm{m} \times 1.0 \mu \mathrm{m}$ was etched by varying the $\mathrm{SF}_{6} / \mathrm{O}_{2}$ gas flow ratio. An anode of SMS of $11 \mu \mathrm{m}-$ height in average showed stable charge/discharge capacity and Coulombic efficiency higher than 99\% for more than 300 cycles, causing no destruction to any part of the Si wafer. The spiky structure turned columnar after cycles, suggesting graded lithiation levels along the length. The present results suggest a strategy to utilize a wafer-based Si material for an anode of a lithium ion battery durable against repetitive lithiation/delithiation cycles. Published by AIP Publishing.

https://doi.org/10.1063/1.4997713
\end{abstract}

\section{INTRODUCTION}

For lithium-ion batteries (LIBs) of next-generation, researches to seek alternative anode materials that would be superior to graphite carbon (theoretical gravimetric specific capacity $C_{\mathrm{m} \text {-th }}=372 \mathrm{~mA} \mathrm{~h} \mathrm{~g}^{-1}$ ) are ongoing. ${ }^{1-9}$ Among the materials with near-zero potential according to $\mathrm{Li} / \mathrm{Li}^{+}$, silicon ( $\mathrm{Si}$ ) is one of the most attractive candidates because of its huge $C_{\mathrm{m} \text {-th }}, 4200 \mathrm{mAhg}^{-1}$ for $\mathrm{Li}_{22} \mathrm{Si}_{5}$ (Ref. 3) or $3579 \mathrm{~mA} \mathrm{~h}^{-1}$ for $\mathrm{Li}_{15} \mathrm{Si}_{4}$ (Ref. 10). This huge capacity, however, implies at the same time that significant volume expansion occurs on $\mathrm{Si}$ during lithiation $(+300 \%$ from $\mathrm{Si}$ to $\left.\mathrm{Li}_{22} \mathrm{Si}_{5}\right){ }^{2,11}$ A low diffusion coefficient of $\mathrm{Li}$ ions in $\mathrm{Si}$ causes selective Li alloying at the surface of the Si material, and thus different volume expansion between the surface and bulk regions, which leads to cracking or pulverization of the bulk $\mathrm{Si}$ material, making the anode fragile and non-durable. ${ }^{3,4}$ Furthermore, this process could lead to a continuous destruction of the solid electrolyte interphase (SEI) layer during the electrode cycling, causing capacity loss (cumulative irreversible capacity). In order to avoid these problems, nanostructured Si materials including nanoparticles, ${ }^{12}$ nanowires, ${ }^{1,13,14}$ nanotubes, ${ }^{3}$ and thin films ${ }^{15}$ have been attempted for their utilization as anodes in LIBs. The critical size of $\mathrm{Si}$ nanowires as anodes of LIBs for being free from destruction was reported to be $\sim 70 \mathrm{~nm}$ (Ref. 16) or $\sim 100 \mathrm{~nm}$ (Ref. 14).

Here, considering the four-fold volume expansion from pure $\mathrm{Si}$ to alloyed $\mathrm{Li}_{22} \mathrm{Si}_{5}$, the ideal design of the anode would be such that the final alloy fills the volume of the electrode space, i.e., the initial $\mathrm{Si}$ material occupies a quarter of the layer in volume. From this viewpoint, we are focusing on $\mathrm{Si}$ nano- or micro-structures prepared by etching Si wafers rather

\footnotetext{
a) Author to whom correspondence should be addressed: jo.sakai@univ-tours.fr
}

than by growing nanowires or nanotubes. We have chosen two types of etched Si wafers, wet-etched porous Si and dryetched microstructured Si. Concerning the former type of wafers, prepared by electrochemical etching in a hydrofluoric acid (HF)-based liquid electrolyte, we have reported that a macroporous Si layer (with pores of 5-8 $\mu \mathrm{m}$ in diameter and $17 \mu \mathrm{m}$ in depth) transplanted onto a copper foil acts as a flexible negative electrode. This anode showed stable cycling performance with a gravimetric specific capacity, $C_{\mathrm{m}}$, of $1360 \mathrm{~mA} \mathrm{~h} \mathrm{~g}^{-1}$, under conditions of a voltage scan range of $0.125-0.7 \mathrm{~V}$ and a current density of $\mathrm{C} / 20 .{ }^{17} \mathrm{We}$ have also reported that a mesoporous $\mathrm{Si}$ wafer (with pores of $60-70 \mathrm{~nm}$ in diameter, $5 \mu \mathrm{m}$ in depth) achieved a higher $C_{\mathrm{m}}$ of $2480 \mathrm{~mA}$ $\mathrm{hg}^{-1}$ (under $0.07-2 \mathrm{~V}, \mathrm{C} / 9$ ) and $1910 \mathrm{mAhg}^{-1}$ (under $0.1-2 \mathrm{~V}, \mathrm{C} / 9$ ) being accompanied by a capacity retention of $97 \%$ for 70 cycles in the latter case. ${ }^{18}$ The advantages of electrochemical etching processes include low cost in production and reproducibility of well-defined porous structures. Yet, neither of our previous works nor the ones by other groups has achieved a wafer-based $\mathrm{Si}$ anode that is free from fading against hundreds of cycling processes. In the case of a LIB prepared on a Si wafer, a diffusion barrier layer is generally inserted between the anode part and the base wafer. ${ }^{11} \mathrm{~A}$ wafer-based Si nanowire anode, prepared by means of a silver nanoparticle-assisted electroless chemical etching process, has been reported with their cycling properties, however, for no more than ten cycles and with current-potential profiles that are more or less inconsistent with other Si anodes. ${ }^{19}$ If a wellcyclable wafer-based $\mathrm{Si}$ anode would be realized without a barrier layer, it could be an elemental technology for embedding a LIB into a CMOS device chip.

The latter type of etched $\mathrm{Si}$, prepared by a cryogenic $\mathrm{SF}_{6} / \mathrm{O}_{2}$ ion etching process, ${ }^{20}$ is also interesting for 
application as an anode of LIBs. By exposing a blank silicon surface cooled at a cryogenic temperature to a $\mathrm{SF}_{6} / \mathrm{O}_{2}$ plasma, one can achieve a microstructure that consists of spikes or needles with tall pyramid-like outlines and graded widths that increase from the surface to the bottom, ${ }^{21}$ in contrast to electrochemically etched porous $\mathrm{Si}$ structures with a constant width. Si wafers with such microstructures, the socalled black-Si, have been mainly applied for solar cells, thanks to their function of antireflection. ${ }^{22}$ A trial of using black-Si as the anode of LIBs has already been reported by Lee et al., with a huge initial specific capacity, but an early decline of the specific capacity in charge/discharge cycling. ${ }^{9}$ In the present study, we adopted black-Si consisting of pyramid-like spikes as the anode material of Li half-cells and examined their charge/discharge properties. The results revealed that the half-cells using black-Si anodes with certain sizes of the spiky microstructure (SMS), even with the bulk Si wafer under it, showed excellent cyclability.

\section{EXPERIMENTAL}

SMS were prepared on $0.5 \mathrm{~mm}$-thick, n-type Si (100) wafers with a resistivity of $\sim 10 \Omega \mathrm{cm}$ by means of a cryogenic deep reactive ion etching (DRIE) process in an inductively coupled plasma (ICP) reactor (Alcatel, 601E) using a mixture of $\mathrm{SF}_{6}$ and $\mathrm{O}_{2}$ gases. ${ }^{23}$ The wafer chuck was cooled by liquid nitrogen. The etching was performed under fixed conditions such as a source power of $1000 \mathrm{~W}$, a self-bias voltage of $-40 \mathrm{~V}$, an $\mathrm{SF}_{6}$ flow rate of $200 \mathrm{sccm}$, a total pressure of $3 \mathrm{~Pa}$, a sample temperature of $-130^{\circ} \mathrm{C}$, and an etching duration of $10 \mathrm{~min}$. Only the $\mathrm{O}_{2}$ flow rate was varied among the samples from 20 to $40 \mathrm{sccm}$, so that the $\mathrm{SF}_{6} / \mathrm{O}_{2}$ gas flow ratio was controlled (hereafter, we label the SMS Si sample prepared with the $\mathrm{O}_{2}$ flow of $\mathrm{xx}$ sccm as SMSxx). The cross sections and top view images of etched Si wafers were observed with a scanning electron microscope (SEM; Zeiss, Supra 40).

Electrochemical half-cells, each of which is based on a SMSxx chip $(x x=20,25,30,35,40)$ as a working electrode and a piece of Li foil (Sigma Aldrich) as both reference and counter electrodes, were prepared in an argon-filled glovebox (with water and oxygen levels below $10 \mathrm{ppm}$ ) within the form of two-electrode 2032-type coin cells. Before introduction, the SMS Si chips, cut from the wafer, were slightly etched in diluted HF, and their back surface was coated with titanium (Ti) by a dc sputtering deposition method. The etching in HF was necessary; otherwise, no circuit current occurred in the half-cells, apparently due to a remaining passivation layer $\mathrm{SiO}_{x} \mathrm{~F}_{y}$ that had been formed on the surface of SMS during the plasma process. ${ }^{9}$ The Ti coating is also for obtaining good electrical contact between the Si wafer and the coin cell part. The electrodes were separated by the pair of a polypropylene membrane (Celgard, 2400) and a glass microfiber membrane (Whatman, GF/C) impregnated with a liquid electrolyte, which was $1 \mathrm{M} \mathrm{LiPF}_{6}$ dissolved in a 1:1:3 mixture of ethylene carbonate (EC), propylene carbonate (PC), and dimethyl carbonate (DMC). The Li foil piece, circular with a diameter of $10 \mathrm{~mm}$, was put on the membrane so as to cover the area of the SMS chip.
Electrochemical measurements were carried out for all the half-cells of SMSxx with a versatile multi potentiostat (Biologic, VMP3). Galvanostatic charge/discharge cycling was performed at different charge limits $\left(Q_{\mathrm{L}}\right)$ and current densities $\left(J_{\mathrm{a}}\right)$. The maximum $Q_{\mathrm{L}}$ value was set to be around $75 \%$ of the theoretical capacity calculated from $C_{\mathrm{m} \text {-th }}$ (3579 $\mathrm{mA} \mathrm{h} \mathrm{g}^{-1}$ ) and areal density $M$ (mass per area) of the SMS layer. Here, $M$ was roughly estimated by performing binary processing onto a top-view SEM image of the sample to deduce the nominal areal occupancy of spikes, which was then multiplied by the averaged height of spikes and the density of $\mathrm{Si}\left(2.33 \mathrm{~g} \mathrm{~cm}^{-3}\right)$. The charge steps were terminated with respect to the charge limit $Q_{\mathrm{L}}$, whereas the discharge steps were terminated by the higher potential limit, $1.2 \mathrm{~V}$ vs. $\mathrm{Li} / \mathrm{Li}^{+}$. Note that the lower potential limit was also set at $0.02 \mathrm{~V}$, which was actually never reached during the cycling. After selected discharge processes, electrochemical impedance measurements were performed under open circuit potential between $1 \mathrm{MHz}$ and $10 \mathrm{mHz}$ with a signal amplitude of $7 \mathrm{mV}$. Si anodes were taken out from the cells after charge/discharge cycles and washed with DMC in the glovebox to capture post-mortem SEM images (Zeiss, ULTRA Plus).

\section{RESULTS AND DISCUSSION}

Sizes of the SMS strikingly depended on the $\mathrm{SF}_{6} / \mathrm{O}_{2}$ ratio, as summarized in Fig. 1(a). A smaller $\mathrm{O}_{2}$ flow resulted in longer spikes, even for the same etching duration of $10 \mathrm{~min}$. Note that the length (height) of the spikes does not correspond to the depth of etching, as explained later. The averaged length of the spikes ranged from $21 \mu \mathrm{m}$ in SMS20 to $2.1 \mu \mathrm{m}$ in SMS40, and the averaged width from $1.0 \mu \mathrm{m}$ to $0.22 \mu \mathrm{m}$. The process of spike formation is schematically explained in Fig. 1(b). As the etching advanced, the merging of neighboring pores [Fig. 1(b-ii)] results in a pointed spike with a pyramid-like "frame structure" having its top underneath the initial wafer surface [Fig. 1(b-iii)]. The pyramidlike frame structure implies a graded thickness of the $\mathrm{Si}$ walls, thinner at the top and thicker at the base. The structure difference between our black-Si and Lee's one, with cylinders and no thin walls, ${ }^{9}$ originates in the different processes, which in the latter case consists of alternate etching/depositing steps with $\mathrm{SF}_{6}$ and $\mathrm{C}_{4} \mathrm{~F}_{8}$ gases, respectively (Bosch process). Figures 1(c) and 1(d) show cross-sectional and topview SEM images, respectively, of SMS25. One can easily find $\mathrm{Si}$ walls with the local thickness thinner than $100 \mathrm{~nm}$ in Fig. 1(d).

Here, we show the results of electrochemical characterization on a Li-ion half-cell with a chip of SMS25 (with the averaged height and width of $11 \mu \mathrm{m}$ and $0.75 \mu \mathrm{m}$, respectively, and an area of $36 \mathrm{~mm}^{2}$ ) as a representative. Figure 2(a) shows the charge/discharge curves for the first 5 cycles of galvanostatic cycling. In the 1 st cycle, a rapid decrease of the potential from the open circuit voltage of the electrode $(2.4 \mathrm{~V})$ to $\sim 90 \mathrm{mV}$ was observed. As expected, the Si-Li alloying reaction was confirmed in a potential region below $0.5 \mathrm{~V} .{ }^{10,24-26}$ Then, the charging continued until the capac-

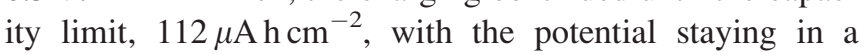




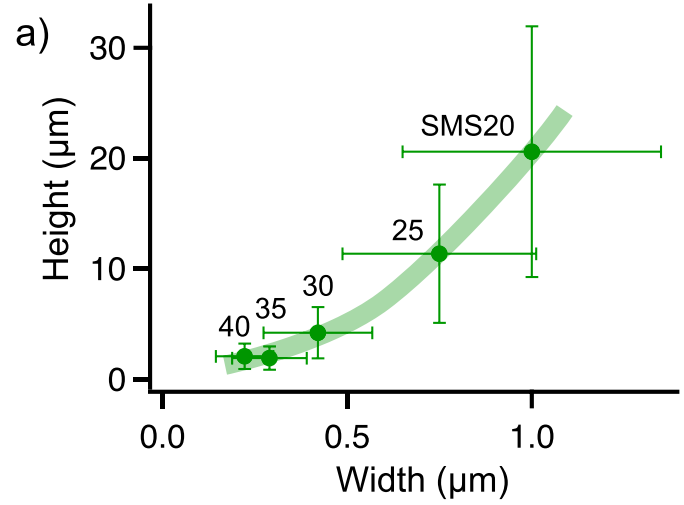

b).
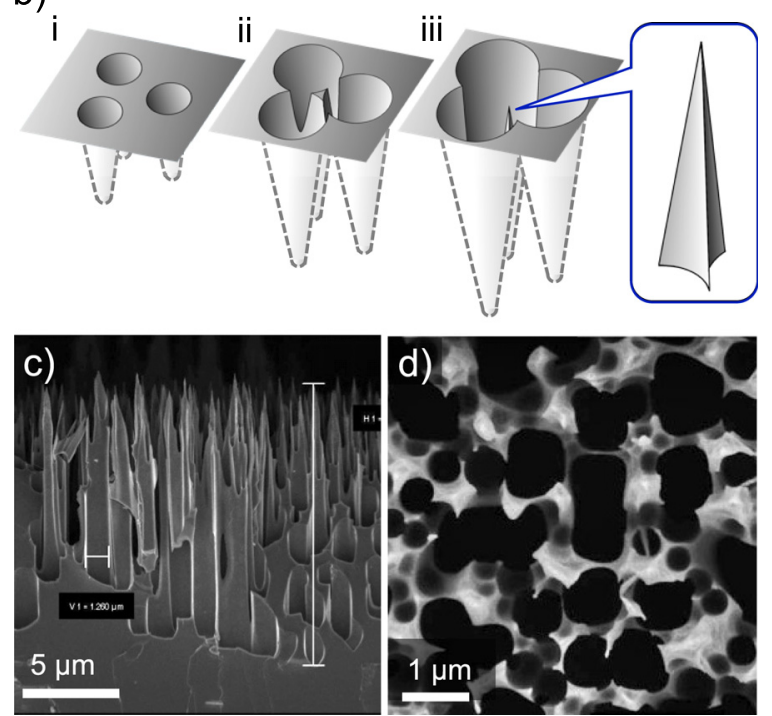

FIG. 1. (a) Averaged height and width of spikes in various SMS samples. Error bars represent the scattering of sizes among actual spikes. (b) Schematic of the process for SMS. A pyramid-like spike with a "frame structure" appears at step iii. (c) and (d) Cross-sectional and top-view SEM images, respectively, of SMS25.

region between 50 and $90 \mathrm{mV}$. The stable potential indicates the formation of a single $\mathrm{Li}-\mathrm{Si}$ phase during the charging from 30 to $112 \mu \mathrm{A} \mathrm{h} \mathrm{cm}^{-2}$. The charge consumption between $1.7 \mathrm{~V}$ and $0.5 \mathrm{~V}$ is mainly due to the irreversible reduction of the electrolyte, which leads to the SEI layer formation. ${ }^{1}$ The Coulombic efficiency was therefore relatively low for the 1st cycle and increased during the following charge/discharge cycles, indicating stabilization of the electrode/electrolyte interface that allows reversible lithiation/delithiation of the electrode. Figure 2 (b) shows $\mathrm{d} Q / \mathrm{d} V$ profiles during the first 5 cycles, which clearly highlight the lithiation process evidenced by the charge consumption below $0.4 \mathrm{~V}$. The appearance of multiple peaks in the $\mathrm{d} Q / \mathrm{d} V$ profiles of both charge and discharge processes, whose intensity indicates the rate of lithiation of materials at each potential, is consistent with previous reports. ${ }^{1,6,9,11,25,26}$ Two peaks that appeared at 0.3 and $0.45 \mathrm{~V}$ during the discharge process from the 1 st cycle are typical signals of delithiation from amorphous $\mathrm{Li}_{x} \mathrm{Si}$, suggesting that Li alloying of crystalline $\mathrm{Si}$ has already occurred in the lithiation process before, probably at potentials under $0.4 \mathrm{~V} .{ }^{24}$ From 2nd cycles, lithiation of amorphous Si started, as indicated by the peaks at $0.20-0.22 \mathrm{~V}$ and $0.25-0.28 \mathrm{~V}$. a)

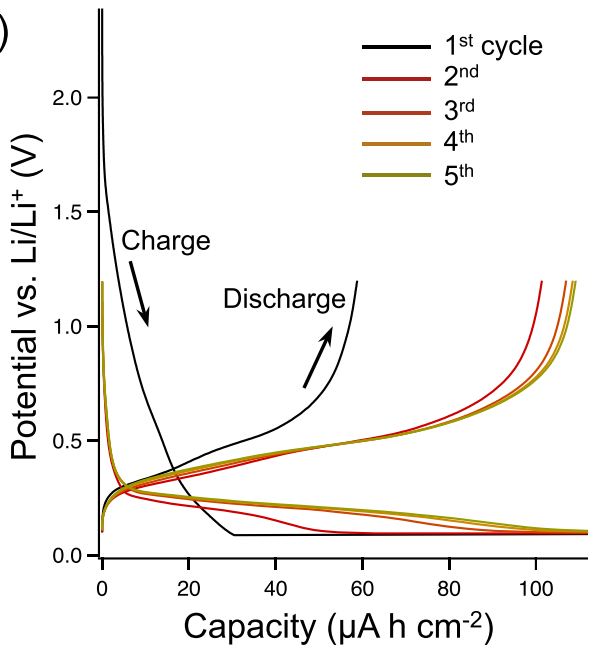

b)

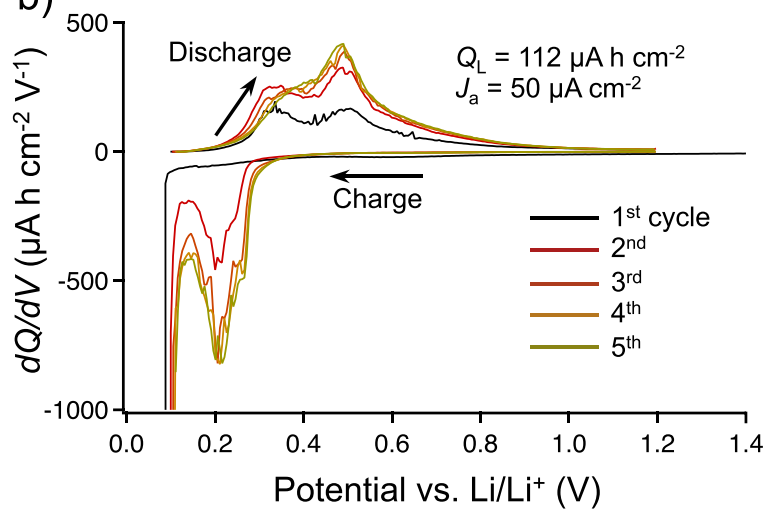

FIG. 2. (a) Charge/discharge curves and (b) $\mathrm{d} Q / \mathrm{d} V$ profiles during first 5 cycles of galvanostatic cycling on a half-cell with SMS25.

The position and the amplitude of these peaks slightly evolved during the first few cycles and were then stabilized after the 3rd cycle, similarly to typical delithiation peaks at $0.30-0.35 \mathrm{~V}$ and $0.48-0.50 \mathrm{~V}$.

Figure 3(a) shows the evolution of the discharge capacity per area, $C_{\mathrm{a}}$, of the same half-cell as in Fig. 2, under the conditions of charge limits $\left(Q_{\mathrm{L}}\right)$ and current densities $\left(J_{\mathrm{a}}\right)$ changed during the cycling. For all $Q_{\mathrm{L}}$ attempted, from 112 to $448 \mu \mathrm{A} \mathrm{h} \mathrm{cm}^{-2}$, the cycling was quite stable with a Coulombic efficiency higher than $99 \%$ except for the first few cycles due to the irreversible charge consumption during the SEI layer formation. However, the improvement of the Coulombic efficiency indicates that a stable SEI layer was formed relatively fast. Several $\mathrm{d} Q / \mathrm{d} V$ profiles are depicted from the cycling with various $Q_{\mathrm{L}}$ and shown in Fig. 3(b), indicating that all the lithiation and delithiation peaks are enhanced as the charge limit $Q_{\mathrm{L}}$ increases. A slight shift of the lithiation peak at $\sim 0.25 \mathrm{~V}$ to the lower potential as $Q_{\mathrm{L}}$ increases may indicate the increase of averaged $x$ in $\mathrm{Li}_{x} \mathrm{Si}$. To confirm the reproducibility and the durability, we prepared another half-cell with SMS25 (chip area of $48 \mathrm{~mm}^{2}$ ) and performed a longer cycling on it. During the whole period of the experiment until 342 cycles, where $J_{\mathrm{a}}$ varied between 200 and $500 \mu \mathrm{A} \mathrm{cm}{ }^{-2}$ during the first 106 cycles then fixed at $400 \mu \mathrm{A} \mathrm{cm}^{-2}$ after 107 th cycle, full charge/discharge occurred up to the charge limit without fading, 
a)
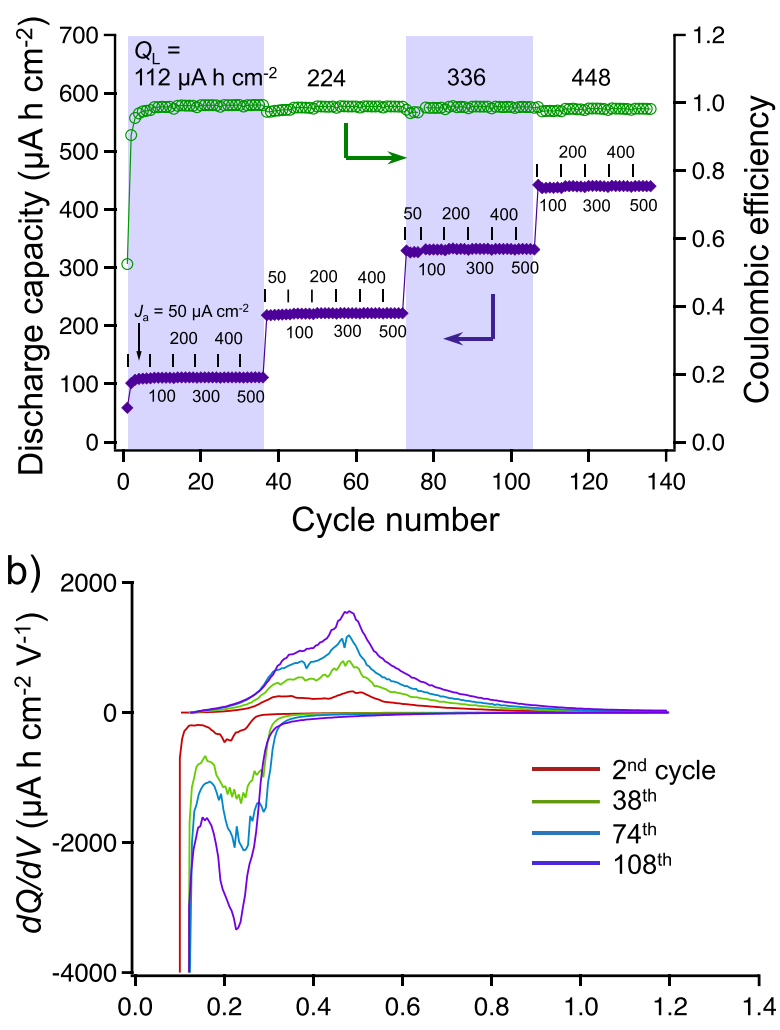

c)

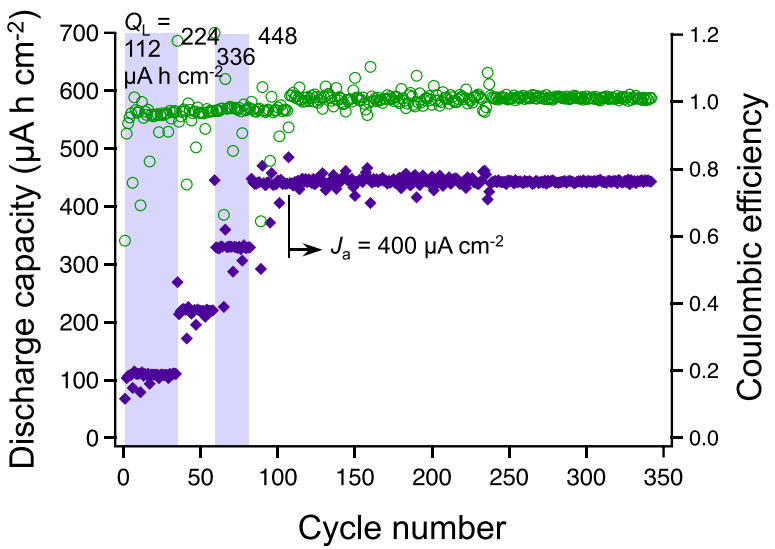

FIG. 3. (a) Evolution of discharge capacity and Coulombic efficiency on the same half-cell as shown in Fig. 2 during 136 cycles, with varying charge limit $Q_{\mathrm{L}}$ and current density $J_{\mathrm{a}}$. (b) The $\mathrm{d} Q / \mathrm{d} V$ profiles at 2 nd, 38th, 74th, and 108 th cycles. $Q_{\mathrm{L}}$ for each cycle was $112,224,336$, and $448 \mu \mathrm{A} \mathrm{h} \mathrm{cm}^{-2}$, respectively. (c) Evolution of discharge capacity and Coulombic efficiency on another half-cell with SMS25 during 342 cycles.

indicating good stability of the SMS structure [Fig. 3(c)]. It is noteworthy that the charge/discharge cycles on a Si anode, not separated from the $\mathrm{Si}$ wafer, without any diffusion barrier layer, resulted in such excellent stability.

Besides, the divergence of negative $\mathrm{d} Q / \mathrm{d} V$ occurred at the end of charge processes from the 1st cycle throughout the measured cycles [Figs. 2(b) and 3(b)]. This divergence at around $0.1 \mathrm{~V}$ of potential, which corresponds to the lithiation of crystalline $\mathrm{Si}^{24}$ is understood as a part of the bulk $\mathrm{Si}$ being lithiated in every charging step up to $\geq 108$ th cycles. However, the insertion of Li into the bulk Si was minimized, thanks to the charge limit that was set considering the volume of the SMS layer; without this charge limit, i.e., if the charge process was limited only in potential, the lithiation would continue until the volume expansion would cause the destruction of the $\mathrm{Si}$ anode. One reason for better cyclability in the present results compared to previous ones on a black Si-based half-cell is obviously this limitation of charge. The present experiment, as well as previous studies, strongly suggests the significance of limiting the charge in charge/discharge cycling on $\mathrm{Si}$ anodes that are connected to the bulk $\mathrm{Si}$ wafer. ${ }^{9,18}$

In the present paper, we describe the capacity and the current density per unit area, instead of those per unit mass, because of the difficulty in precisely estimating the mass of the Si material that actually takes part in lithiation. At the beginning, we roughly estimated from SEM images the areal density, $M$, of the SMS layer in SMS25 to be $1.7 \times 10^{-4} \mathrm{~g}$ $\mathrm{cm}^{-2}$. This $M$ would convert the areal capacity $C_{\mathrm{a}}$ of $448 \mu \mathrm{A}$ $\mathrm{h} \mathrm{cm}{ }^{-2}$ to a gravimetric capacity $C_{\mathrm{m}}$ of $2665 \mathrm{~mA} \mathrm{~h} \mathrm{~g}^{-1}$, and the areal current density $J_{\mathrm{a}}$ of $500 \mu \mathrm{A} \mathrm{cm}^{-2}$ to a gravimetric current density $J_{\mathrm{m}}$ of $3.0 \mathrm{~A} \mathrm{~g}^{-1}$ (or to a C-rate $J_{\mathrm{C}}$ of $0.7 \mathrm{C}$, where $1 \mathrm{C}=4.2 \mathrm{~A} \mathrm{~g}^{-1}$ ). This combination of $C_{\mathrm{m}}$ and $J_{\mathrm{C}}$ values is, however, exceptional in comparison to previous reports on $\mathrm{Si}$ anodes. It is a general nature of the electrodes that a higher current density results in less specific capacity. One can find a universal relationship between gravimetric specific capacities and C-rates for various types of $\mathrm{Si}$ anodes previously reported, at least in a low $J_{\mathrm{C}}$ region up to $\sim 2 \mathrm{C}$, as plotted in Fig. 4. ${ }^{1,5,6,8,27}$ The point of $0.7 \mathrm{C}$ and $2665 \mathrm{~mA} \mathrm{~h} \mathrm{~g}^{-1}$ (Point A in Fig. 4) seems to position out of this universal relationship. This anomaly should originate in the discrepancy between estimated and actual $M$ values. We now try an approximation by drawing a line of $\log C_{\mathrm{m}}-\log J_{\mathrm{C}}=$ constant, as shown in Fig. 4. Depending on $M$, the point $\left(J_{\mathrm{C}}, C_{\mathrm{m}}\right)$ moves on this line, due to the relationships $C_{\mathrm{m}}=C_{\mathrm{a}} / M$ and $J_{\mathrm{C}}=J_{\mathrm{a}} /\left(C_{\mathrm{m} \text {-th }} M\right)$. Although it is extremely difficult to obtain the true $M$ value, it is certain that the true $\left(J_{\mathrm{C}}, C_{\mathrm{m}}\right)$ point exists somewhere on this

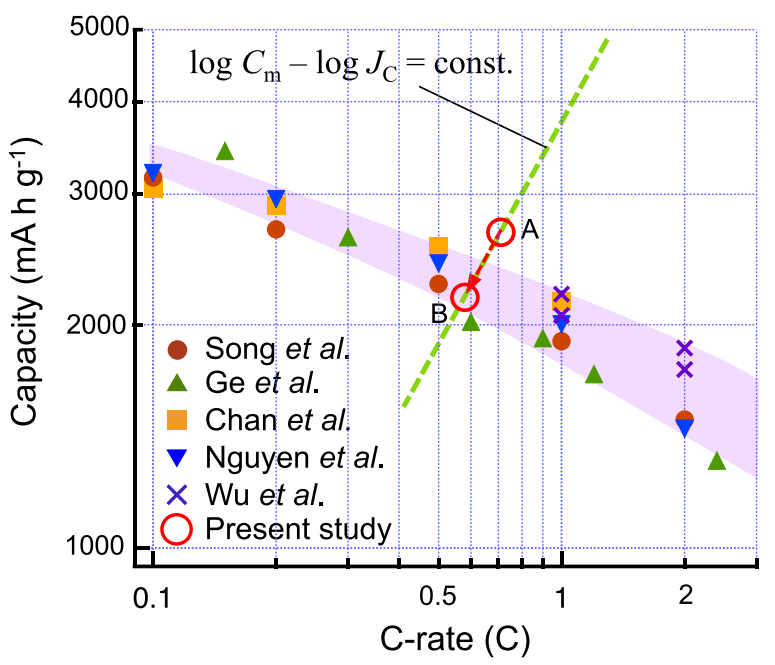

FIG. 4. Relationship between gravimetric specific capacities $\left(C_{\mathrm{m}}\right)$ and C-rates $\left(J_{\mathrm{C}}\right)$ on various types of $\mathrm{Si}$ anodes (depicted from Refs. $1,5,6,8$, and 27). Points A and B show the present result assuming areal densities of the $\mathrm{Si}$ anode of $1.7 \times 10^{-4}$ and $2.2 \times 10^{-4} \mathrm{~g} \mathrm{~cm}^{-2}$, respectively. Dashed line represents a line of constant $\left(\log C_{\mathrm{m}}-\log J_{\mathrm{C}}\right)$ line that passes Point A. 

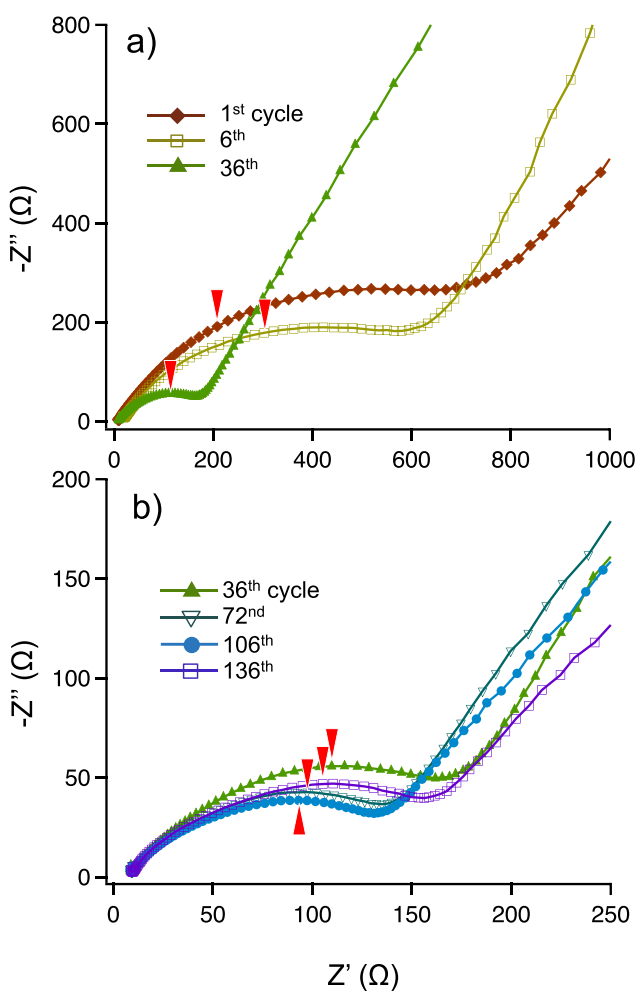

FIG. 5. Nyquist diagrams of impedance measurements performed after (a) 1st, 6th, 36th cycles, and (b) 36th, 72nd, 108th, 136th cycles, on the same half-cell as shown in Fig. 2. Triangles indicate the points for a frequency of $435 \mathrm{~Hz}$ in each run.

line. It seems more realistic to assume that our point also obeys the universal relationship, positioning at Point B in Fig. 4, for example, which corresponds to an $M$ of $2.2 \times 10^{-4} \mathrm{~g}$ $\mathrm{cm}^{-2}$, i.e., the actual $M$ of the active material was higher than that estimated from SEM images. If it is the case, it may imply that lithiation/delithiation occurred not only within the SMS layer but also in the bulk region. This picture is consistent with the divergence of discharge capacity at $0.1 \mathrm{~V}$ described above [Figs. 2(b) and 3(b)].

0 cycle
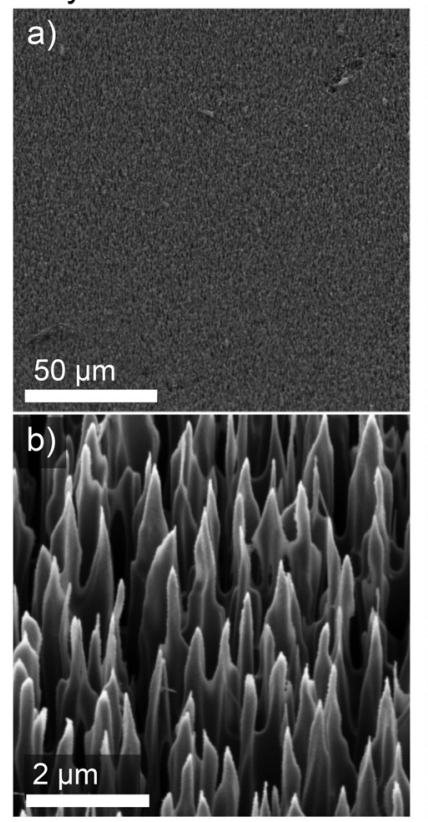

After 136 cycles
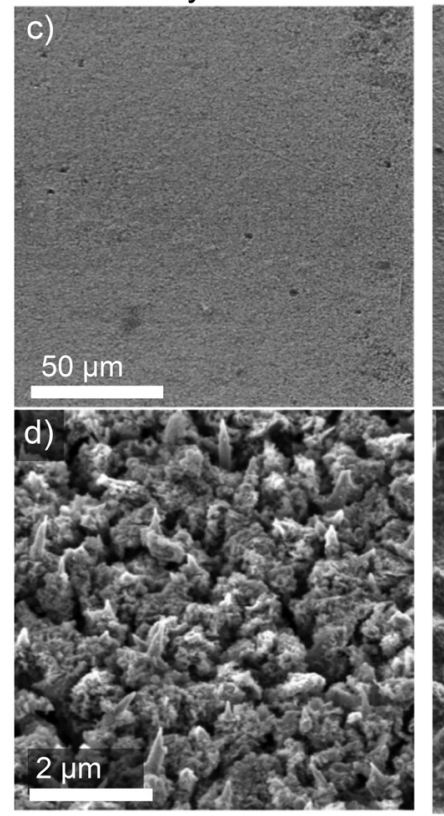

Figure 5 shows Nyquist diagrams based on electrochemical impedance measurements that were performed after certain charge/discharge cycles in Fig. 3(a). The semicircle with the characteristic frequency of several hundred $\mathrm{Hz}(435 \mathrm{~Hz}$ in this case) is generally attributed to the SEI layer, whereas the sloped line in the low frequency region represents the diffusion of $\mathrm{Li}$ ions into the bulk active material. ${ }^{4,28,29}$ The present cycling exhibited the drastic shrinkage of the semicircle during the first 36 cycles, followed by stabilization or a slight increase for further cycling, which behavior is consistent with previous reports on Si-based anodes. ${ }^{4,28}$ Ruffo et al. attributed the shrinkage of the semicircle at mid-frequency $(250 \mathrm{~Hz}$ of characteristic frequency) during the first few cycles in their Si nanowire anode to the "fixation" of the SEI/liquid electrolyte interface. ${ }^{4}$ Then, the stabilization of the ac impedance signal and the diameter of the highfrequency semicircle can be explained by the stabilization of the interface, indicating that non-significant volume or surface changes are occurring on the electrode after the huge evolution observed during the first cycles. These observations are also supported by the SEM observation.

Figure 6 shows post-mortem SEM images of SMS25 electrodes after experiencing 136 and 342 charge/discharge cycles [corresponding to Figs. 3(a) and 3(c), respectively], together with the images of as-prepared SMS25 (namely, 0 cycle). The gap among pyramid-like spikes at the beginning [Fig. 6(b)] has been partially filled as the spikes deformed at the stage of 136th cycle [Fig. 6(d)], and has almost disappeared before the 342nd cycle [Fig. 6(f)]. We found neither crack on the surface nor detachment of the microstructured layer even after 342 cycles [Fig. 6(e)]. To understand what was occurring inside the SMS layer during cycling, an image at the edge of the SMS chip is informative. In a SEM image, at the edge of the SMS25 chip after 342 cycles [Fig. 7(a)], we can confirm that the microstructure layer still consists of a few $\mu$ m-wide "fibers" even though the top surface shows the feature of a continuous plane.
After 342 cycles

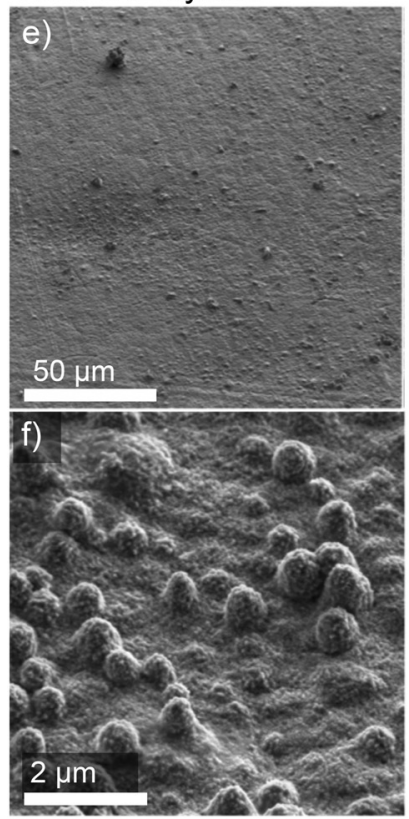

FIG. 6. Oblique-view SEM images of SMS25 chips (a), (b) as prepared, (c), (d) after 136 charge/discharge cycles, and (e), (f) after 342 cycles. (a), (c), (e) are in a lower magnification and (b), (d), (f) are in a higher one. 


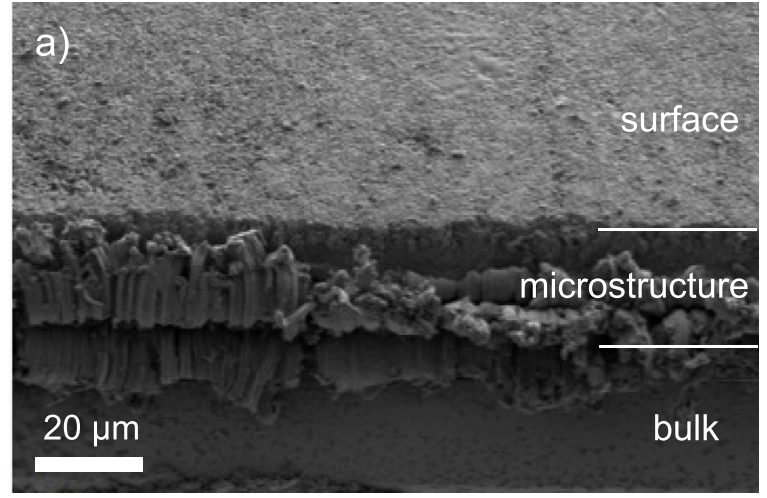

b)

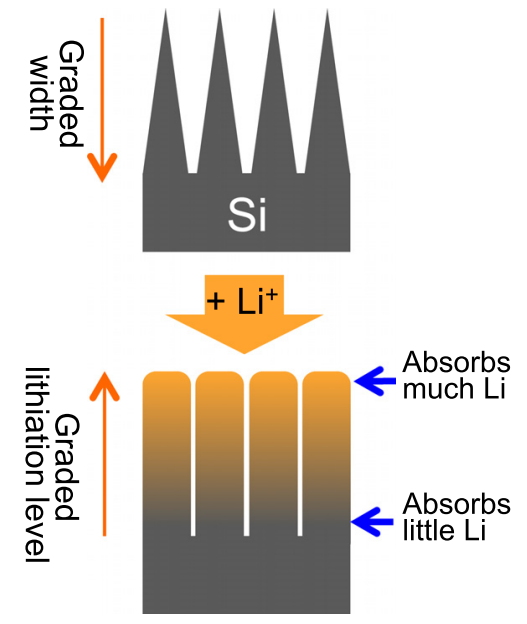

FIG. 7. (a) Oblique-view SEM image of the edge of an SMS25 chip after 342 cycles. (b) Schematic of the model that the microstructure transforms from spiky into columnar during Li ion insertion.

As one side of the microstructure layer was open, the arrays of fibers near the edge were allowed to point tilted directions, clearly showing their fiber-like features. Note that the width of the fibers is almost constant from the bottom to the top, i.e., the microstructure has transformed from spiky into columnar. We also note that even the Si wafer base, as well as the columns, is free from any visible cracking. The quasismooth surface, the constant width of the fibers, and the lack of cracking all suggest the stabilization of the microstructure through the cycling, rather than the destruction of it.

On the basis of these experimental facts, we speculate a model on the deformation of SMS according to charge/discharge cycling, as illustrated in Fig. 7(b). When Li ions are inserted into a $\mathrm{Si}$ matrix of different thickness, the thicker (thinner) part would suffer from more (less) stress by the deformation. Especially, the thinnest parts with the thickness of less than $100 \mathrm{~nm}$ would be free from any destruction. ${ }^{14}$ Therefore, $\mathrm{Li}$ ions prefer entering the $\mathrm{Si}$ matrix at the thinner parts, where the volume expansion would cause less mechanical stress. In the case of a pyramid-like spike with graded widths, the top (bottom) part with a smaller (larger) width is supposed to absorb more (less) Li ions, until the width becomes uniform, i.e., the spike transforms into a column. It may also be possible to consider a picture that the top parts automatically absorb more Li ions because the electric field concentrates at the top with small radii or with the shortest distance to the counter electrode. The evaluation of possible effects caused by these factors would bring about the strategies for designing anode forms and would require further studies. In the final form, the lithiation level from a microstructure to bulk regions would be graded along the depth, causing little risk of a point of discontinuous lithiation level, which could be the reason of destruction. This picture explains the fact that the present wafer-based $\mathrm{Si}$ anode did not show any cracks, in contrast to the previous ones.

The experiments on half-cells with SMS chips other than SMS25 (not shown) resulted in a tendency that the spikes with too short lengths are not durable for charge/ discharge cycling. The discharge capacity of the cell with SMS40 (with the averaged height and width of 2.1 and $0.22 \mu \mathrm{m}$, respectively) has faded after 14 cycles, being accompanied by the cracking of the bulk Si layer. We summarize the results that the spikes of at least $5 \mu \mathrm{m}$-long, of pyramid-like outline with the graded width, with the thinnest part of less than $100 \mathrm{~nm}$, as well as the limitation of charge, are important for the excellent cyclability of a wafer-based SMS Si anode. The "frame structure" [Fig. 1(b-iii)] is probably advantageous not only because of the thinness of the walls but also because of the mechanical robustness in comparison with other forms of material of same volume.

\section{CONCLUSIONS}

We attempted to use SMS of Si (black-Si), prepared by a cryogenic DRIE process with an $\mathrm{SF}_{6} / \mathrm{O}_{2}$ gas mixture, for the anodes of Li half-cells. An SMS anode with spikes of $11 \mu \mathrm{m}$ in averaged height revealed excellent stability without any destruction up to at least 340 charge/discharge cycles with a Coulombic efficiency higher than $99 \%$ under a limited capacity. The deformation of the microstructure from spiky to columnar implied the graded lithiation level along the length, which could result in the absence of a point with an abrupt change in mechanical stress. The present results suggest a possibility to prepare a LIB on a Si wafer, using cryoetched Si SMS as its anode. Thus, the way to integrate LIBs into industrial Si CMOS technology would be opened.

\section{ACKNOWLEDGMENTS}

This work was supported by Région Centre, France, through the BLaDES project (Contract No. 2011 00068694) and the French Government through the Investissements d'Avenir Tours2015 project.

${ }^{1}$ C. K. Chan, H. Peng, G. Liu, K. McIlwrath, X. F. Zhang, R. A. Huggins, and Y. Cui, Nat. Nanotechnol. 3, 31 (2008).

${ }^{2}$ S. D. Beattie, D. Larcher, M. Morcrette, B. Simon, and J.-M. Tarascon, J. Electrochem. Soc. 155, A158 (2008).

${ }^{3}$ M.-H. Park, M. G. Kim, J. Joo, K. Kim, J. Kim, S. Ahn, Y. Cui, and J. Cho, Nano Lett. 9, 3844 (2009).

${ }^{4}$ R. Ruffo, S. S. Hong, C. K. Chan, R. A. Huggins, and Y. Cui, J. Phys. Chem. C 113, 11390 (2009).

${ }^{5}$ T. Song, J. Xia, J.-H. Lee, D. H. Lee, M.-S. Kwon, J.-M. Choi, J. Wu, S. K. Doo, H. Chang, W. I. Park, D. S. Zang, H. Kim, Y. Huang, K.-C. Hwang, J. A. Rogers, and U. Paik, Nano Lett. 10, 1710 (2010).

${ }^{6}$ H. T. Nguyen, F. Yao, M. R. Zamfir, C. Biswas, K. P. So, Y. H. Lee, S. M. Kim, S. N. Cha, J. M. Kim, and D. Pribat, Adv. Energy Mater. 1, 1154 (2011).

${ }^{7}$ H. Wu and Y. Cui, Nano Today 7, 414 (2012).

${ }^{8}$ M. Ge, J. Rong, X. Fang, and C. Zhou, Nano Lett. 12, 2318 (2012). 
${ }^{9}$ G. Lee, S. L. Schweizer, and R. B. Wehrspohn, J. Vac. Sci. Technol. A 32, 061202 (2014).

${ }^{10}$ M. N. Obrovac and L. Christensen, Electrochem. Solid-State Lett. 7, A93 (2004).

${ }^{11}$ L. Baggetto, R. A. H. Niessen, F. Roozeboom, and P. H. L. Notten, Adv. Funct. Mater. 18, 1057 (2008).

${ }^{12}$ D. Mazouzi, N. Delpuech, Y. Oumellal, M. Gauthier, M. Cerbelaud, J. Gaubicher, N. Dupré, P. Moreau, D. Guyomard, L. Roué, and B. Lestriez, J. Power Sources 220, 180 (2012).

${ }^{13}$ B. Laï, L. Eude, J.-P. Pereira-Ramos, C. S. Cojocaru, D. Pribat, and E. Rouvière, Electrochim. Acta 53, 5528 (2008).

${ }^{14}$ K. Kang, H.-S. Lee, D.-W. Han, G.-S. Kim, D. Lee, G. Lee, Y.-M. Kang, and M.-H. Jo, Appl. Phys. Lett. 96, 053110 (2010).

${ }^{15}$ T. Takamura, S. Ohara, M. Uehara, J. Suzuki, and K. Sekine, J. Power Sources 129, 96 (2004)

${ }^{16}$ Z. Ma, T. Li, Y. L. Huang, J. Liu, Y. Zhou, and D. Xue, RSC Adv. 3, 7398 (2013).

${ }^{17}$ E. Luais, J. Sakai, S. Desplobain, G. Gautier, F. Tran-Van, and F. Ghamouss, J. Power Sources 242, 166 (2013).

${ }^{18}$ E. Luais, F. Ghamouss, J. Wolfman, S. Desplobain, G. Gautier, F. TranVan, and J. Sakai, J. Power Sources 274, 693 (2015).
${ }^{19}$ K. Peng, J. Jie, W. Zhang, and S.-T. Lee, Appl. Phys. Lett. 93, 033105 (2008).

${ }^{20}$ H. Jansen, M. de Boer, R. Legtenberg, and M. Elwenspoek, J. Micromech. Microeng. 5, 115 (1995).

${ }^{21}$ R. Dussart, X. Mellhaoui, T. Tillocher, P. Lefaucheux, M. Volatier, C. Socquet-Clerc, P. Brault, and P. Ranson, J. Phys. D: Appl. Phys. 38, 3395 (2005).

${ }^{22}$ J. Yoo, G. Yu, and J. Yi, Mater. Sci. Eng., B 159-160, 333 (2009).

${ }^{23}$ R. Dussart, T. Tillocher, P. Lefaucheux, and M. Boufnichel, J. Phys. D: Appl. Phys. 47, 123001 (2014).

${ }^{24}$ R. A. Huggins, J. Power Sources 81-82, 13 (1999).

${ }^{25}$ M. Green, E. Fielder, B. Scrosati, M. Wachtler, and J. S. Moreno, Electrochem. Solid State Lett. 6, A75 (2003).

${ }^{26}$ H.-C. Shin, J. A. Corno, J. L. Gole, and M. Liu, J. Power Sources 139, 314 (2005).

${ }^{27}$ H. Wu, G. Chan, J. W. Choi, I. Ryu, Y. Yao, M. T. McDowell, S. W. Lee, A. Jackson, Y. Yang, L. Hu, and Y. Cui, Nat. Nanotechnol. 7, 310 (2012).

${ }^{28}$ J. Guo, A. Suna, X. Chen, C. Wang, and A. Manivannan, Electrochim. Acta 56, 3981 (2011).

${ }^{29}$ Y.-M. Lin, K. C. Klavetter, P. R. Abel, N. C. Davy, J. L. Snider, A. Heller, and C. B. Mullins, Chem. Commun. 48, 7268 (2012). 